\title{
Polyamine Concentration in Rat Milk and Food, Human Milk, and Infant Formulas ${ }^{1}$
}

\author{
N. ROMAIN, G. DANDRIFOSSE, F. JEUSETTE, AND P. FORGET
}

Laboratory of Biochemistry and General Physiology [N.R., G.D.] and Data-Processing Centre [F.J.], University of Liege, Liege, Belgium; and Department of Pediatrics, University of Maastricht, Maastricht, Netherlands [P.F.]

\begin{abstract}
The polyamine concentration in rat milk and food, human milk, and infant formulas was estimated by HPLC. In rat milk, the concentration of putrescine and spermine was low (generally under $2.5 \mathrm{nmol} \cdot \mathrm{mL}^{-1}$ for putrescine and under $1 \mathrm{nmol} \cdot \mathrm{mL}^{-1}$ for spermine). The spermidine concentration was higher and seemed to increase during lactation. The rat food was richer in polyamines than the rat milk (about 150 times for putrescine and spermine, about 30 times for spermidine). We already proved that ingestion of spermine or spermidine can induce precocious maturation of the rat intestine. The present observations suggest that polyamines contained in rat food could play an important role in postnatal maturation of the rat intestine. The polyamine concentration of human milk was measured from 60 different mothers during a period extending from the 1st wk to the 6th mo of lactation. Great variation was observed. During the 1 st mo of lactation, the general pattern was as follows: putrescine concentration generally varied little (from 1 to $3 \mathrm{nmol} \cdot \mathrm{mL}^{-1}$ ), spermine and spermidine concentrations showed a similar pattern (the highest values appeared at the end of the 1st wk of suckling). After the 4th mo of lactation, putrescine concentration increased slightly, whereas spermine and spermidine concentration stayed almost stable. The concentrations of polyamines in 18 powdered milks for babies were estimated. Spermine and spermidine contents were lower than those in human milk. A protective effect of spermine or spermidine against alimentary allergies is suggested. (Pediatr Res 32: 58-63, 1992)
\end{abstract}

In the rat, maturation of the gastrointestinal tract occurs during the 3 rd postnatal wk (for example, see 1-4). Before maturation, the lactase $\mathrm{sp}$ act of the small bowel mucosa is high, whereas sucrase and maltase are very low. This immature mucosa is characterized histologically by the presence of enterocytes containing a large supranuclear vacuole and an apical canalicular system probably involved in nonspecific protein transfer through the gut wall. At the moment of maturation (18th-20th postnatal $\mathrm{d}$, i.e. the time of weaning) mucosal sp act of maltase and sucrase increase dramatically, whereas lactase sp act decreases to very low values. At the same time, enterocytes lose their apical canalicular system as well as their supranuclear vacuole and nonspe-

Received April 11, 1991; accepted January 6, 1992.

Correspondence and reprint requests: Prof. Guy Dandrifosse, Laboratory of Biochemistry and General Physiology, Chemistry Institute, Liege University, Sart Tilman, 4000 Liege, Belgium.

Supported in part by grants from the "Fonds de la Recherche Scientifique Médicale" (9.4511.87 and 3.4535.88F), "La Loterie Nationale" (1987 and 1989), Nutricia Foundation Research, and "les Services de Programmation de la Politique Scientifique" (HH/12/006).

'The text presents research results of the Belgian Incentive Programme "Health Hazards" initiated by the Belgian State-Prime Minister's Service-Science Policy Office. The scientific responsibility is assured by its authors. cific protein absorption ceases ("gut closure"). Various attempts have been made to influence this development sequence (5-12). Whereas various hormones or local mediators have been shown to be involved in the regulatory mechanism of intestinal maturation in suckling rodents, the influence of food or food constitutents has been less thoroughly studied.

In previous studies (13-15), we showed that it was possible to induce precocious intestinal maturation in the rat by giving spermidine or spermine orally, i.e. polycationic substances of low molecular weight that are ubiquitous and are synthesized by all cell types studied. These polyamines were chosen because it is known that these molecules are involved in intestinal growth (16). They are synthesized locally through the induction of ornithine decarboxylase, which is the first enzyme involved in polyamine synthesis. Another reason for our choice was that it has been proved (8) that mucosal polyamine concentrations show a dramatic increase at the moment of postnatal intestinal maturation in the rat. To precisely state the meaning of our observations, we decided to analyze the polyamine content of the rat milk and food. These results are reported below.

Because it is important to know the significance of our findings for human health, we measured the polyamine concentration in infant formulas and in human milk. A high polyamine content in the food of babies could, indeed, be very important for favoring the final maturation steps of their intestine: it is now generally accepted that the intestine of healthy term infants is more permeable to food proteins during the first $3 \mathrm{mo}$ than later in life (17-19); it is acknowledged that, during the period that follows birth, antigenic macromolecules can penetrate the small intestinal mucosal membranes in quantities that may be of immunologic importance $(18,20,21)$.

\section{MATERIALS AND METHODS}

Polyamine concentrations. The polyamine concentrations in the various solutions analyzed were measured by HPLC (22). Solid sulfosalicylic acid $(20 \mathrm{mg})$ was added to $300 \mu \mathrm{L}$ of milk and $300 \mu \mathrm{L}$ of distilled water (MilliQ; Waters Assoc., Millipore Corp., Bedford, MA) or to $50 \mathrm{mg}$ of rat food suspended in $1 \mathrm{~mL}$ of water. Protein precipitation was obtained by leaving the samples overnight at $-20^{\circ} \mathrm{C}$. After centrifugation at $3000 \times g$ for 15 min, aliquots of $200 \mu \mathrm{L}$ of supernatants were used for derivatization.

Dansylation was carried out as described by Bontemps et al. (22). The reproducibility of extraction was tested. It was greater than $95 \%$ for spermine and spermidine and greater than $75 \%$ for putrescine. Repeated injections showed a coefficient of variation lower than $1.5 \%$. The dansylated derivatives of polyamines were separated on a reversed-phase column (Lichrocart RP-18; Merck, Darmstadt, Germany). The polyamine concentrations were expressed in $\mathrm{nmol} \cdot \mathrm{mL}^{-1}$ and the polyamine contents in $\mathrm{nmol} \cdot \mathrm{g}^{-1}$.

Rat milk. Wistar rats were housed in standard conditions. They had free access to water and food (R/S A03, UAR, Epinay- 
sur-Orge, France). The young rats were reared by their natural mothers in the absence of other animals. The room was kept at $23^{\circ} \mathrm{C}$ with $12 \mathrm{~h}$ of daylight.

The polyamine contents of the milk of nine female rats were determined. Milk samples were taken, every $3 \mathrm{~d}$, in the morning throughout the whole lactating period. The she-rat was separated from her young for the night $( \pm 16 \mathrm{~h}$ ). Then, she was anesthetized. To numb the rat, anesthetic (Ketalar, Warner-Lambert, Zaventem, Belgium) was intraperitoneally injected $(0.1 \mathrm{~mL} \cdot 100$ $\mathrm{g}^{-1}$ body weight).

To stimulate milk secretion, oxytocin was subsequently injected intraperitoneally [Syntocinon (Sandoz, Basel, Switzerland): $1 \mathrm{U} \cdot \mathrm{mL}^{-1} ; 0.1 \mathrm{~mL} \cdot 100 \mathrm{~g}^{-1}$ body weight]. Milk was extracted by a homemade breast pump; 0.5 to $2 \mathrm{~mL}$ of milk were collected.

These experiments were performed with the highest standards of humane care with the approval by local committee on animal investigation.

Rat food compounds. Complete rat food (R/S A03) was crushed into powder using a pestle and mortar. Then, $50 \mathrm{mg}$ of rat food powder was suspended in $1 \mathrm{~mL}$ of water containing 10 mg of sulfosalicylic acid. This concentration was chosen after several trials. Such a preparation was made twice. Aliquots were kept at $-20^{\circ} \mathrm{C}$ for at least one night. Dansylation of both extracts was carried out as described above. Two measurements (double injection on HPLC system) were made for each extract.

Human milk. Polyamine concentrations of human milk were determined during the first 6 postnatal mo. When possible, a milk sample was collected each day during the 1st postnatal mo. Afterwards, it was obtained once a week until the end of lactation.

Preliminary studies were undertaken to find out the best moment of sampling during one suckling. Then, the milk samples were collected in a standardized way with the help of the staff of the milk bank of Liege and individual mothers. Milk aliquots were frozen immediately after gathering and kept at $-20^{\circ} \mathrm{C}$ until analysis.

Infant formulas. We measured polyamine concentrations in most commercial infant formulas available on the Belgian market. These powders were diluted as indicated by the manufacturer, just before polyamine dansylation (see above). Two extracts were prepared and two measurements (double injection on HPLC system) were made for each extract.

Statistics. Two different methods were used to study the evolution of polyamine concentrations in rat milk during the entire lactating period $( \pm 25 \mathrm{~d})$. First, a separate regression line was fitted for the data obtained for each rat in which at least three consecutive measurements were available. Slopes and intercepts were then averaged and tested for significance by using $t$ test. Secondly, a regression line was also fitted to all the time-related data, whether from the same or other rats, to assess the overall trend of the variables studied. A similar approach was used for data collected from women's milk. All results were considered to be significant at the $5 \%$ critical level.

\section{RESULTS}

Rat milk. There was no success in milking the she-rats the day after birth. Thus, results were obtained for the period between the 2 nd and the 25 th $d$ after birth. Transversal (or overall) and longitudinal (or individual) analyses of data are reported in Table 1. The measurements showed great individual variability for each polyamine contained in rat milk (transversal analysis). The concentration of putrescine (a diamine) and spermine was quite low (under $2.5 \mathrm{nmol} \cdot \mathrm{mL}^{-1}$ ), except for putrescine in milk secreted at the beginning of lactation, and did not vary much during the lactating period. Longitudinal analyses confirm these observations. The mean of spermidine concentration was higher and seemed to increase during lactation $( \pm 9$ to $>20 \mathrm{nmol}$. $\mathrm{mL}^{-1}$ ), but, looking at individual serial data, we were not able to confirm this finding, possibly because of the limited amount of data.

Rat food. As shown in Table 1, the complete rat food contained large quantities of polyamines.

Human milk. To choose the best conditions to take milk samples, we carried out preliminary studies: $l$ ) estimation of the polyamine concentrations in milk throughout one suckling; 2) evolution of putrescine, spermidine, and spermine concentrations in the course of $1 \mathrm{~d}$ of the 3rd wk of lactation; 3) analysis of polyamine concentration in milk samples taken from both breasts at the end of suckling. These studies showed a great variation in concentrations of spermine and spermidine from one mother to another and differences in the concentration of polyamines between the left and the right breast of a particular mother. Because it appeared that it is psychologically inadvisable to interrupt a baby during breast suckling and that the results may be overvalued by taking a sample at the end of suckling, we decided to take milk from the 2 nd breast before the baby began suckling it (under these conditions, contraction of the breast had already occurred).

Tables 2 and 3 show the results obtained for 60 different mothers. Table 2 concerns the everyday averages for the 1 st mo of lactation and the longitudinal analysis performed in two groups of women (2-12 d after birth and 12-31 d after birth). Table 3 shows the averages of the monthly measurements (obtained once a week) when analyzing milks secreted from the 2 nd mo to the 6 th mo of lactation (transversal analysis) and the results of the longitudinal analysis performed with the data obtained. Great individual variation was observed.

The general pattern of polyamine concentrations in human milk during the 1 st mo of lactation obtained from the longitudinal analysis (Table 2) indicated that: $l$ ) putrescine concentration did not significantly vary, and 2) spermidine and spermine concentrations showed a similar pattern. The highest values appear at the end of the 1st wk of suckling. Some mothers always seem to have quite high or quite low concentrations of putrescine, spermine, and spermidine, which show the same tendency to decrease at the end of the 1 st mo of lactation. However, a firm conclusion could not be drawn. The statistical analysis did not reveal a significant regression slope.

Individual regressions fitted to data obtained between the 5 th wk and the 20th wk of lactation (Table 3) showed that putrescine concentration increased, whereas spermine and spermidine concentration stayed almost constant in human milk. Spermine and spermidine concentration had a tendency to decrease, but not significantly.

Infant formulas. We measured the concentration of polyamines in 18 powdered milks for babies (Table 4). The analyses showed that the concentrations of spermine, spermidine, and putrescine in all tested samples of milk varied between 0 and $0.87,0$ and 2.78 , and 0.62 and $6.07 \mathrm{nmol} \cdot \mathrm{mL}^{-1}$, respectively.

\section{DISCUSSION}

In a previous publication (14), we reported that it is possible to induce precocious intestinal maturation in rats by giving them spermine or spermidine orally. This observation was recently confirmed by another research team (23).

To find out if ingested polyamines can play a role in the normal development of the rat intestine, we estimated the concentration of these substances in rat milk and food.

Our results (Table 1) show that in rat milk the concentration of putrescine and spermine was quite low (less than $2.5 \mathrm{nmol}$. $\left.\mathrm{mL}^{-1}\right)$ (transversal analysis), as pointed out by Pollack et al. (24). This concentration did not vary much during the lactating period (longitudinal analysis), when spermidine concentration was higher and could increase during lactation (from 9 to $>20 \mathrm{nmol}$. $\mathrm{mL}^{-1}$ ).

As shown by the data reported in Table 1, rat food was richer in polyamines than rat milk (approximately 150 times for pu- 
Table 1. Polyamine concentrations $\left(\mathrm{nmol} \cdot \mathrm{mL}^{-1}\right)$ in rat milk during the whole lactating period* 1. Transversal analysis

\begin{tabular}{cccc}
\hline Day after birth & $\begin{array}{c}\text { Putrescine } \\
{[x \pm \text { SEM }(n)]}\end{array}$ & $\begin{array}{c}\text { Spermidine } \\
{[x \pm \text { SEM }(n)]}\end{array}$ & $\begin{array}{c}\text { Spermine } \\
{[x \pm \text { SEM }(n)]}\end{array}$ \\
\hline $1-3$ & $4.25 \pm 1.94(5)$ & $11.11 \pm 1.72(5)$ & $0.38 \pm 0.03(5)$ \\
$7-6$ & $1.58 \pm 0.48(6)$ & $8.94 \pm 0.78(6)$ & $0.27 \pm 0.07(6)$ \\
$10-12$ & $2.21 \pm 0.63(6)$ & $13.10 \pm 3.72(7)$ & $0.53 \pm 0.10(7)$ \\
$13-15$ & $0.87 \pm 0.59(6)$ & $11.91 \pm 2.76(8)$ & $0.57 \pm 0.18(8)$ \\
$16-18$ & $1.00 \pm 0.33(8)$ & $15.12 \pm 2.30(10)$ & $0.60 \pm 0.08(10)$ \\
$19-21$ & $1.60 \pm 0.62(6)$ & $23.70 \pm 4.74(9)$ & $0.89 \pm 0.17(10)$ \\
$22-25$ & $0.83 \pm 0.28(6)$ & $20.50 \pm 2.72(9)$ & $0.91 \pm 0.08(8)$ \\
Rat food & $1.55 \pm 0.54(5)$ & $21.47 \pm 8.51(5)$ & $1.12 \pm 0.40(5)$ \\
& 223 & 442 & 104
\end{tabular}

2. Longitudinal analysis: slopes (b) and intercepts (a) expressed as mean \pm SEM

$$
\begin{array}{rrr}
\text { Putrescine: } a=0.602 \pm 0.465 & \text { Spermidine: } a=11.195 \pm 5.761 & \text { Spermine: } a=0.407 \pm 0.182 \\
b=-0.013 \pm 0.035 & b=0.273 \pm 0.304 & b=0.018 \pm 0.009
\end{array}
$$

Hypothesis that slope is zero cannot be rejected at the $5 \%$ critical level (other explanations in the text)

$* n=$ number of milkings. Polyamine content in rat food is given in $\mathrm{nmol} \cdot \mathrm{g}^{-1}$.

trescine and for spermine, and approximately 30 times for spermidine). Although it may be argued that the wide variation in values obtained when measuring polyamine concentration in rat milk (Table 1) could be due to the treatment of the she-rats to obtain milk and although it is well known that rat feeding does not change abruptly at weaning, it may be suggested that the polyamines found in solid rat food represent a significant increase in the exogenous contribution of these substances in the rat at this moment. The polyamines contained in the solid rat food could thus play an important role in the postnatal maturation of the rat intestine or in the maintenance of a functional stage of the rodent bowel. The latter possibility agrees with results obtained by other authors (16). This hypothesis is further reinforced by the fact that the bacterial flora, another source of exogenous polyamines, grows with the administration of solid food (25).

To evaluate the possible implications of our findings for humans, we measured the polyamine concentration in infant formulas and in human milk.

The following considerations prompted us to carry out these analyses: 1) it is well known that babies often have a high intestinal permeability for food proteins $(17,19,26)$, which could lead to the development of allergic reactions (18), and that rat intestinal maturation is characterized by a decrease in intestinal permeability for macromolecules $(4,27) ; 2)$ it has been noted that allergy problems seem to be less frequent in breast-fed children when compared with bottle-fed infants (for example, see 18). This observation suggests that when compared with human milk, infant formulas might lack one or several compounds important for intestinal maturation, for example spermine or spermidine.

Preliminary results showed that great variation exists in the concentration of milk polyamines from one mother to another. Even for a given mother, such variation was observed according to the time of day, the stage of suckling, or the breast chosen. It has also been observed for other milk components (for a review, see 28 and 29).

To avoid psychologic problems for the mother and her baby and to reduce the apparent variation in the milk-polyamine concentrations, we decided to perform a systematic analysis by taking milk samples from the second breast just before the baby began sucking it.

Great individual variation was recorded (Tables 2 and 3). We can nevertheless determine the general pattern of polyamine concentrations during lactation from individual regression analyses. Polyamine concentration varied little throughout the lactating period. Spermine and spermidine concentrations seemed to have higher values at the end of the 1st wk of suckling than at the end of the 1st mo of lactation. A similar observation was partly reported elsewhere by other authors (30). After the 5th wk of lactation, putrescine concentration increased slightly in milk, whereas spermine and spermidine contents were almost constant but had a tendency to decrease. Several mothers seem to have consistently quite high or quite low concentrations of putrescine, spermine, and spermidine. These individual variations may be due, for example, to the diet, the way of life, or the genetic background of each mother. If our reasoning concerning the role of polyamines in the prevention of allergies is correct, a parallel could be established between low concentrations of polyamines in breast milk and a predisposition of children to become allergic. To check this hypothesis, a long-term follow-up of these infants will be undertaken.

The polyamine concentration in 18 powdered milks for babies was measured (Table 4). The putrescine concentration was highly variable but had values that were sometimes higher than those of human milk (Tables 2 and 3). The spermine concentration was always lower in infant formula than in human milk. The spermidine concentration of human milk was also higher than that of infant formula (Tables 2-4), as pointed out by other authors (12).

The results presented above clearly indicate that the spermine and spermidine intake of breast-fed babies is higher than that of infant formula-fed babies. If our observations showing that spermine or spermidine ingestion induces precocious intestinal maturation of the intestine in rat (14) could be extended to man, they could mean that breast-feeding favors intestinal maturation in babies, for example, by bringing about a decrease in protein permeability.

It may, of course, be argued that polyamine metabolism in the intestinal mucosa enables natural maturation to occur, especially because the putrescine concentration of powdered milk is not very different from that of mother's milk. Such a possibility may not be ruled out. However, we have to remember that we showed that putrescine ingestion in unweaned mice did not induce intestinal maturation (31). On the contrary, we noticed signs of partial involution of the intestinal epithelium.

From our results, it may be proposed that the possible protective effect of human milk against allergies, which has been reported in the literature (for example, see 18), could be explained at least partially by its high level of polyamines, especially spermine (see above).

Such a hypothesis is reinforced by other observations that we made and summarized elsewhere (13) indicating that pancreatic 
Table 2. Polyamine concentrations $\left(\mathrm{nmol} \cdot \mathrm{mL}^{-1}\right)$ in human milk during the 1 st mo of lactation* 1. Transversal analysis

\begin{tabular}{|c|c|c|c|}
\hline Day after birth & $\begin{array}{c}\text { Putrescine } \\
{[x \pm \operatorname{SEM}(n)]}\end{array}$ & $\begin{array}{c}\text { Spermidine } \\
{[x \pm \operatorname{SEM}(n)]}\end{array}$ & $\begin{array}{c}\text { Spermine } \\
{[x \pm \operatorname{SEM}(n)]}\end{array}$ \\
\hline 2 & $0.72 \quad$ (1) & 3.73 & $3.12 \quad$ (1) \\
\hline 3 & $2.04 \pm 0.86$ & $3.58 \pm 0.73$ & $3.25 \pm 0.48$ \\
\hline 5 & $1.80 \pm 0.94(13)$ & $4.14 \pm 0.76(13)$ & $4.44 \pm 1.06(13)$ \\
\hline 6 & $1.03 \pm 0.13(13)$ & $5.06 \pm 0.64(13)$ & $5.22 \pm 0.71(13)$ \\
\hline 7 & $1.29 \pm 0.21(12)$ & $7.11 \pm 1.09(12)$ & $6.63 \pm 1.36(12)$ \\
\hline 10 & $1.02 \pm 0.17(16)$ & $7.44 \pm 0.91(16)$ & $8.29 \pm 1.32(16)$ \\
\hline 11 & $1.34 \pm 0.23(14)$ & $8.00 \pm 1.29(15)$ & $7.71 \pm 1.25(15)$ \\
\hline 12 & $1.10 \pm 0.11(19)$ & $6.91 \pm 0.70(21)$ & $6.77 \pm 0.95(20)$ \\
\hline 13 & $1.26 \pm 0.19(19)$ & $8.17 \pm 1.09(19)$ & $7.75 \pm 1.23(19)$ \\
\hline 14 & $1.08 \pm 0.14(19)$ & $5.69 \pm 1.12(19)$ & $6.13 \pm 1.54(18)$ \\
\hline 15 & $1.59 \pm 0.28(16)$ & $7.31 \pm 1.22(17)$ & $8.23 \pm 1.65(16)$ \\
\hline 20 & $1.27 \pm 0.22(15)$ & $5.17 \pm 0.59(16)$ & $6.06 \pm 1.57(15)$ \\
\hline 21 & $1.07 \pm 0.23(13)$ & $6.14 \pm 1.19(12)$ & $6.35 \pm 1.34(13)$ \\
\hline 22 & $1.13 \pm 0.18(13)$ & $5.78 \pm 1.13(13)$ & $5.40 \pm 1.39(12)$ \\
\hline 23 & $1.43 \pm 0.75(13)$ & $6.64 \pm 1.10(12)$ & $8.06 \pm 1.54(11)$ \\
\hline 24 & $1.79 \pm 0.49(12)$ & $6.98 \pm 1.52(11)$ & $7.60 \pm 1.48(10)$ \\
\hline 25 & $2.15 \pm 0.85(12)$ & $6.07 \pm 1.07(12)$ & $5.67 \pm 1.03(10)$ \\
\hline 26 & $2.39 \pm 0.81(11)$ & $4.02 \pm 0.94(10)$ & $5.18 \pm 1.08$ \\
\hline 27 & $1.81 \pm 0.66$ & $4.30 \pm 0.97$ & $5.28 \pm 0.83$ \\
\hline 28 & $1.20 \pm 0.22$ & $2.94 \pm 0.58$ & $4.19 \pm 1.05$ \\
\hline 29 & $1.56 \pm 0.49$ & $5.29 \pm 0.85$ & $4.37 \pm 0.75$ \\
\hline 30 & $1.35 \pm 0.27$ & $3.96 \pm 0.18$ & $4.67 \pm 0.51$ \\
\hline 31 & $1.34 \pm 0.22$ & $6.75 \pm 0.14$ & $5.83 \pm 0.82$ \\
\hline
\end{tabular}

2. Longitudinal analysis in two groups of women (2-12) and (12-31): slopes (b) and intercepts (a) are expressed as mean \pm SEM

$$
\begin{aligned}
& \text { Putrescine }(2-12): \mathrm{a}=1.295 \pm 0.895 \\
& \mathrm{~b}=-0.019 \pm 0.083 \\
& \text { Spermidine (2-12): } \mathrm{a}=3.021 \pm 1.423 \\
& b=0.416 \pm 0.197 \\
& \text { Spermine (2-12): } \mathrm{a}=3.868 \pm 1.907 \\
& \mathrm{~b}=0.309 \pm 0.239 \\
& \begin{array}{llr}
\text { Putrescine (12-31): } & \mathrm{a}=0.880 \pm 0.551 \\
& \mathrm{~b}=0.026 \pm 0.033 \\
\text { Spermidine (12-31): } & \mathrm{a}=9.624 \pm 2.535 \\
& \mathrm{~b}=-0.205 \pm 0.119 \\
\text { Spermine (12-31): } & \mathrm{a}=8.366 \pm 2.929 \\
& \mathrm{~b}=-0.129 \pm 0.137
\end{array}
\end{aligned}
$$

\begin{tabular}{|c|c|c|c|}
\hline Months after birth & $\begin{array}{c}\text { Putrescine } \\
{[x \pm \operatorname{SEM}(n)]}\end{array}$ & $\begin{array}{c}\text { Spermidine } \\
{[x \pm \operatorname{SEM}(n)]}\end{array}$ & $\begin{array}{c}\text { Spermine } \\
{[x \pm \operatorname{SEM}(n)]}\end{array}$ \\
\hline 2 & $0.90 \pm 0.12(13)$ & $3.85 \pm 0.85(13)$ & $3.44 \pm 0.72(13)$ \\
\hline 3 & $1.10 \pm 0.14$ & $2.08 \pm 0.50$ & $2.78 \pm 1.85$ \\
\hline 4 & $0.79 \pm 0.15$ & $3.16 \pm 0.54$ & $3.50 \pm 1.01$ \\
\hline 5 & $0.84 \pm 0.16$ & $1.85 \pm 0.70$ & $2.15 \pm 1.46$ \\
\hline 6 & $0.87 \pm 0.35$ & $2.98 \pm 1.40$ & $2.33 \pm 1.15$ \\
\hline
\end{tabular}

Hypothesis that slope is zero cannot be rejected at the $5 \%$ critical level (other explanations in the text)

${ }^{*} n=$ number of samples (one sample for one mother).

Table 3. Polyamine concentrations (nmol. $\mathrm{mL}^{-1}$ ) of human milk from the 2 nd to the 6 th mo of lactation* 1. Transversal analysis

2. Longitudinal analysis: slopes (b) and intercepts (a) expressed as mean \pm SEM

$$
\begin{array}{rrrr}
\text { Putrescine: } \mathrm{a}=-1.330 \pm 0.574 & \text { Spermidine: } \mathrm{a}=4.947 \pm 2.418 & \text { Spermine: } \mathrm{a}=1.938 \pm 2.408 \\
\mathrm{~b}=0.183 \pm 0.066 & \mathrm{~b}=-0.217 \pm 0.213 & \mathrm{~b}=-0.195 \pm 0.459
\end{array}
$$

Slope significantly increases in the case of putrescine

Hypothesis that slope is zero cannot be rejected at the $5 \%$ critical level in the case of spermidine and spermine

\footnotetext{
$* x=$ mean of the results obtained during the indicated month; $n=$ number of samples.
} 
Table 4. Polyamine concentrations in infant formulas*

\begin{tabular}{|c|c|c|c|}
\hline & Putrescine & Spermidine & Spermine \\
\hline \multicolumn{4}{|l|}{ Nutricia } \\
\hline \multirow[t]{2}{*}{ Peptijunior } & 1.07 & 0.07 & 0.08 \\
\hline & 0.86 & 0.11 & 0.11 \\
\hline \multirow[t]{2}{*}{ Nutrisoja } & 0.84 & 2.33 & 0.44 \\
\hline & 0.64 & 2.78 & 0.43 \\
\hline \multirow[t]{2}{*}{ Nutrimel } & 3.32 & 0.24 & 0.13 \\
\hline & 2.61 & 0.15 & 0.18 \\
\hline \multirow[t]{2}{*}{ Almiron 1} & 1.83 & 0.00 & 0.11 \\
\hline & 1.92 & 0.10 & 0.11 \\
\hline \multirow[t]{2}{*}{ Almiron M2 } & 1.28 & 0.14 & 0.16 \\
\hline & 1.17 & 0.10 & 0.20 \\
\hline \multicolumn{4}{|l|}{ Nestlé } \\
\hline \multirow[t]{2}{*}{ Nan H.A. } & 3.79 & 0.34 & 0.00 \\
\hline & 4.33 & 0.39 & 0.10 \\
\hline \multirow[t]{2}{*}{ Nan } & 0.94 & 0.27 & 0.15 \\
\hline & 0.71 & 0.22 & 0.12 \\
\hline \multirow[t]{2}{*}{ Alfaré } & 1.24 & 1.06 & 0.48 \\
\hline & 1.23 & 1.03 & 0.35 \\
\hline \multicolumn{4}{|l|}{ Milupa } \\
\hline \multirow[t]{2}{*}{ Préaptamil } & 1.52 & 0.22 & 0.11 \\
\hline & 1.45 & 0.22 & 0.13 \\
\hline \multirow[t]{2}{*}{ Aptamil I } & 2.57 & 0.58 & 0.17 \\
\hline & 2.41 & 0.60 & 0.15 \\
\hline \multirow[t]{2}{*}{ Aptamil II } & 4.56 & 0.51 & 0.47 \\
\hline & 4.56 & 0.47 & 0.44 \\
\hline \multirow[t]{2}{*}{ Aptamil H.A. } & 2.38 & 0.25 & 0.13 \\
\hline & 2.00 & 0.31 & 0.09 \\
\hline \multirow[t]{2}{*}{ Nektarmil } & 2.39 & 0.23 & 0.27 \\
\hline & 2.90 & 0.31 & 0.18 \\
\hline \multirow[t]{2}{*}{ Milumel 1} & 3.79 & 0.39 & 0.32 \\
\hline & 3.87 & 0.44 & 0.42 \\
\hline \multirow[t]{2}{*}{ Milupa som } & 0.62 & 0.35 & 0.07 \\
\hline & 0.63 & 0.35 & 0.08 \\
\hline \multirow[t]{2}{*}{ Milupa HN25 } & 6.07 & 1.73 & 0.74 \\
\hline & 5.82 & 1.75 & 0.87 \\
\hline \multicolumn{4}{|l|}{ Guigoz } \\
\hline \multirow[t]{2}{*}{ Guigoz I } & 2.20 & 0.25 & 0.33 \\
\hline & 2.34 & 0.24 & 0.38 \\
\hline \multirow[t]{2}{*}{ Nativa } & 1.64 & & 0.25 \\
\hline & 1.54 & 0.56 & 0.30 \\
\hline
\end{tabular}

* Results are expressed in $\mathrm{nmol} \cdot \mathrm{mL}^{-1}$ of milk diluted as indicated by the manufacturer. Each value is the mean of two measurements. Each formula is sampled twice.

maturation in the rat also seems to be accelerated by ingestion of spermine. Increased amounts of proteolytic enzymes could be secreted in unweaned rats receiving this polyamine orally, a process that would increase hydrolysis of proteins in chyme. Such an effect would increase the degradation of potentially allergenic substances. When added to a decrease in permeability to macromolecules, it would diminish the amount of allergens reaching the intestinal submucosa and thus would allow a better maturation of the immune system in susceptible children.

Of course, the best way to prove our suggestions would be to increase the amount of polyamines in infant formulas and to prove that newborn children who receive such powdered milks are less frequently subject to symptoms of allergy than newborn children fed with infant formulas currently sold on the Belgian market. We hope to be able to undertake these experiments and the necessary epidemiologic study in the near future.

Acknowledgments. The authors thank M. Klimek-Cuvelier, P. Pagnoul, and J.-P. Chessa for their technical assistance and A. Philippart for her help in preparation of the manuscript.

\section{REFERENCES}

1. Crane RK 1968 A concept of the digestive-absorptive surface of the small intestine. In: Code CF, Heidel W (eds) Handbook of Physiology, Section 6. The Alimentary Canal. Williams \& Wilkins, Baltimore, pp 2535-2542

2. Eastwood GL 1977 Gastrointestinal epithelial renewal. Gastroenterology 72:962-975

3. Henning SJ, Kretchmer N 1973 Development of intestinal function in mammals. Enzyme 15:3-23

4. Udall JN, Pang K, Fritze L, Keinman R, Walker WA 1981 Development of gastrointestinal mucosal barrier. I. The effect of age on intestinal permeability to macromolecules. Pediatr Res 15:241-244

5. Bustamante S, Neal D, Yamada K, Koldovsky O 1982 Thyroxin-evoked increase of sucrase activity in lower villus in the jejunum of adrenalectomized suckling rats. J Pediatr Gastroenterol Nutr 1:587-590

6. Doell RR, Kretchmer N 1964 Intestinal invertase. Precocious development of activity after injection of hydrocortisone. Science 143:42-44

7. Koldovsky O 1981 Developmental, dietary and hormonal control of intestinal disaccharidases in mammals (including man). In: Randle PJ, Steiner DF, Whelan WJ (eds) Carbohydrate Metabolism and Its Disorders. Academic Press, New York, pp 481-522

8. Luk GD, Marton LJ, Baylin SB 1980 Ornithine decarboxylase is important in intestinal mucosal maturation and recovery from injury in rats. Science 210:195-198

9. Malo C, Ménard D 1983 Synergistic effects of insulin and thyroxine on the differentiation and proliferation of epithelial cells of suckling mouse small intestine. Biol Neonate 44:177-184

10. Marton GR, Henning SJ 1982 Relative importance of corticosterone and thyroxine in the postnatal development of sucrase and maltase in rat small intestine. Endocrinology 111:912-918

11. Moog F, Denes AE, Powel PN 1973 Disaccharidases in the small intestine of the mouse: normal development and influence of cortisone, actinomycin D and cycloheximide. Dev Biol 35:143-159

12. Yeh KY, Moog F 1978 Influence of the thyroid and adrenal glands on the growth of the intestine of the suckling rat, and on the development of intestinal alkaline phosphatase and disaccharidase activities. J Exp Zool 200:337-348

13. Dandrifosse G, Forget P, Romain N, Deloyer P, Wéry I 1991 Maturation précoce de l'intestin du rat par la spermine: résultats et perspectives. In Moulinoux J-P, Quemener V (eds) Les Polyamines. Aspects Chimiques, Rôles Biologiques et Applications Medicales. Flammarion Médecine-Sciences, Paris, pp 237-247

14. Dufour C, Dandrifosse G, Forget P, Vermesse F, Romain N, Lepoint A 1988 Spermine and spermidine induce intestinal maturation in the rat. Gastroenterology 95:112-116

15. Georges P, Dandrifosse G, Vermesse F, Forget P, Deloyer P, Romain N 1990 Reversibility of spermine-induced intestinal maturation in the rat. Dig Dis Sci 35:1528-1536

16. Luk GD 1990 Polyamines in intestinal growth. Biochem Soc Trans 18:19901991

17. Eartham EJ, Lichauco T, Grady MI, Walker WA 1978 Antigenicity of infant formulas: role of immature intestine on protein permeability. $J$ Pediatr 93:561-564

18. Iyngkaran N, Yadav M 1987 Food allergy. In: March MN (ed) Immunopathology of the small intestine. John Wiley \& Sons Ltd, pp 415-449

19. Roberton DM, Paganelli R, Dinwiddie R, Levinsky RJ 1982 Milk antigen absorption in the preterm and term neonate. Arch Dis Child 57:369-372

20. Fälth-Magnusson KE, Kjellman NIM, Sundqvist T 1984 Intestinal permeability in healthy and allergic children before and after sodium-cromoglycate treatment assessed with different-sized poly-ethyleneglycols (PEG 400 and PEG 1000). Clin Allergy 14:277-286

21. Jackson PG, Lessof WH, Baker RWR, Serrett J, McDonald DM 1981 Intestinal permeability in patients with eczema and food allergy. Lancet 1:1285-1286

22. Bontemps J, Laschet J, Dandrifosse G, Van Cutsem JL, Forget P 1984 Analysis of dansyl derivatives of di- and polyamines in mouse brain, human serum and duodenal biopsy by high-performance liquid chromatography on a standard reversed-phase column. J Chromatogr 311:59-67

23. Wil GE, Daly AS, Bennett G 1990 Effects of exogenous polyamines on postnatal intestinal development. Gastroenterology 98:A435(abstr)

24. Pollack PF, Koldovsky O, Nishioka K 1990 Polyamine content of rat and human milk and infant formula. Pediatr Res 27:289(abstr)

25. Osborne DL, Seidel ER 1990 Microflora-derived polyamines modulate obstruction-induced colonic mucosal hypertrophy. Am J Physiol 258:6576-6584

26. Jakobsson I, Lindberg T, Lothe L, Axelsson I, Benediktsson B 1986 Human $\alpha$-lactalbumin as a marker of macromolecular absorption. Gut 27:10291034

27. Clarke RM, Hardy RN 1969 The use of [ ${ }^{125}$ I] polyvinylpyrrolidone $\mathrm{K} 60$ in the 
quantitative assessment of the uptake of macromolecular substances by the intestine of the young rat. J Physiol 204:113-125

28. Jenness R 1979 The composition of human milk. Semin Perinatol 3:225-239

29. Morriss FH, Brewer ED, Spedale SB, Riddle L, Temple DM, Caprioli RM, West MS 1986 Relationship of human milk pH during course of lactation to concentrations of citrate and fatty acids. Pediatrics 78:458-464
30. Sanguansermsri J, György P, Zilliken F 1974 Polyamines in human and cow's milk. Am J Clin Nutr 27:859-865

31. Etienne-Poncin A, Dandrifosse G, Forget P, Lepoint A 1990 Evolution of some biochemical characteristics of the intestinal mucosa during the first postnatal weeks in C57 mice. Effects of thyroxine and putrescine. J Pediatr Gastroenterol Nutr 9:375-382 